\title{
Comparison of Seminal Superoxide Dismutase (SOD) Activity Between Elite Athletes, Active and Non Active Men
}

\author{
Bakhtyar Tartibian ${ }^{1}$, Behzad Hajizadeh Maleki ${ }^{1}$, Asghar Abbasi², \\ Mehdi Eghbali ${ }^{3}$, Siamak Asri-Rezaei ${ }^{3}$ and Hinnak Northoff ${ }^{4}$ \\ ${ }^{1}$ Department of Cellular and Molecular Exercise Physiology, \\ Faculty of Physical Education and Sport Science, Urmia University, Urmia \\ 2Institute of Sport Science, University of Tuebingen \\ ${ }^{3}$ Department of Clinical Science, Faculty of Veterinary Medicine, \\ Urmia University, Urmia \\ 4Institute of Clinical and Experimental Transfusion Medicine (IKET), \\ University of Tuebingen \\ 1,3 Iran \\ 2,4 Germany
}

\section{Introduction}

It is increasingly recognized that reactive oxygen species (ROS) originating from the spermatozoa as well as from the leukocytes are of significant pathophysiological importance in the etiology of male infertility (Iwasaki and Gagnon, 1992; Zini et al., 1993; Ochsendorf et al., 1994; Shekarriz et al., 1995; Smith et al., 1996; Agarwal et al., 2006; Tremellen, 2008). ROS, defined as including oxygen ions, free radicals and peroxides, may cause infertility by two principal mechanisms. First, ROS damage the sperm membrane which in turn reduces the sperm's motility and ability to fuse with the oocyte. Secondly, ROS directly damage sperm DNA, compromising the paternal genomic contribution to the embryo (Tremellen, 2008). Due to their high content of polyunsaturated fatty acids and their capacity to generate ROS, human spermatozoa are very sensitive to oxidative stress (Aitken and Clarkson, 1987; Aitken et al., 1989; Smith et al., 1996). To protect spermatozoa from oxidative damage, seminal plasma is endowed with numerous enzymatic antioxidants (AOs) such as superoxide dismutase (SOD), catalase and glutathione peroxidase (Fujii et al., 2003; Garrido et al., 2004; Murawski et al., 2007). It has recently been reported, that superoxide anion $\left(\mathrm{O}_{2}\right)$ may be involved in fatty-acid peroxidation (Niess and Simon, 2007). Superoxide dismutase (SOD) and catalase inactivate the superoxide anion $\left(\mathrm{O}_{2}\right)$ and peroxide $\left(\mathrm{H}_{2} \mathrm{O}_{2}\right)$ radicals by converting them into water and oxygen. SOD as an important element of seminal plasma superoxide anion scavenging capacity plays an essential role in maintaining the balance between ROS generation and degradation. Decrease of its capacity can result in abnormal sperm motility determined as sperm hyperactivation, and hence infertility (De Lamirande and Gagnon, 1993). The addition of SOD to sperm in culture has been confirmed to protect 
them from oxidative attack (Kobayashi et al., 1991). Although some investigators have shown no association between SOD activity and male fertility (Miesel et al., 1997; Zini et al., 2000; Hsieh et al., 2002), others have reported a reduction in seminal plasma SOD activity in infertile males (Alkan et al., 1997; Sanocka et al., 1997; Siciliano et al., 2001). Recently Murawski et al. (2007) reported a significantly lower semen SOD activity in infertile males, as compared with normospermic men. They showed a positive correlation between SOD activity in seminal plasma and semen quality parameters - sperm concentration and overall motility, which are regarded as most important for normal fertilizing ability of the spermatozoa (Murawski et al., 2007).

Physical exercise has been shown to increase ROS and oxidative stress causing disruptions of homeostasis. Given that generation of oxidative stress is a natural part of physically active people may be susceptible to ROS-induced damage in sperm motility and male infertility, depending on the exercise mode, intensity, and duration as well as antioxidant capacity. Exercise training, on the other hand, has been shown to have modifying effects on oxidative stress, depending on training load, training specificity and the basal level of training. Growing evidence suggests that aerobic exercise training can result in an augmented SOD activity and a reduction in lipid peroxidation (Mena et al., 1991; Ortenblad et al., 1997; Ji, 1998; Suzuki and Ohno, 2000; Niess et al., 2007). It is well documented that due to intensive training programs, trained and athletic people have developed total antioxidant capacity, and in particular high levels of SOD, in several tissues (Banfi et al., 2006; Dekany et al., 2006; Tayler et al., 2006). However, our knowledge about antioxidant capacity in seminal plasma of athletic and trained men is less than meager, and it was up to now unclear if and under which conditions exercise training may influence seminal antioxidant capacity. Nonetheless, the amounts of enzymatic antioxidants in human semen have been well measured in normal and infertile men (Nissen and Kreysel, 1983; Jeuilin et al., 1989; Kobayashi et al., 1991; Alkan et al., 1997; Miesel et al., 1997; Sanocka et al., 1997; Zini et al., 1993).

Taken together, considering the probable positive correlation and beneficial impact of SOD activity on human semen quality parameters and male fertility on the one hand, and the fact that the SOD and antioxidant capacity of various tissues are highly different between individuals with different level of physical fitness on the other hand, we wanted to find an answer to the question if the SOD activity of seminal plasma is different in individuals with different levels of physical activity. Thus, the purpose of this study was to evaluate the SOD activity in elite athletes, recreationally active and non active men.

\section{Materials and methods}

\subsection{Subjects}

A total of 40 semen samples were obtained from investigated groups in this study (Table1). Of these, 15 samples were obtained from competitive elite athletes (e.g. including wrestlers, runners, football players, and swimmers) who were regularly training 4-5 days per week (Elite group). Thirteen samples were provided by non-obese and physically active males (active group) who participated in educational or recreational physical activities for $4-5 \mathrm{~h}$ per week. And 12 samples were obtained from healthy males who had a sedentary lifestyle without practicing in any sport for at least 6 months prior to study (control group). Physical activity of subjects was assessed by a questionnaire and subjects were matched based on training status and training quantity. 
To be eligible to participate in the study, subjects were required to meet the following criteria: 1) unmarried men 18-28 year of age; 2) in good health, as determined by a normal physical examination and routine laboratory tests within the previous year; 3 ) no history of chronic disease, including reproductive disorders; 4) no history of use of medications that could alter the H-P-G axis, such as anabolic steroids; 5) regular eating patterns and no history of depressive illness; 6) normal physical and sexual development; 7) not working in professions where the activity might influence reproductive capacity; 8) no relevance previous surgery (eg, vasectomy reversal or varicocele removal) ; and 9) appropriate history of physical activity for the different groups described above (Lucía et al., 1996; Di Luigi et al., 2001). Informed consent was obtained from each subject. Before the initiation of the study protocol, each of them was introduced to the methods of this investigation. The Human Subject Internal Review Board committee of the Urmia University of IRAN approved the study (approval number 03/686).

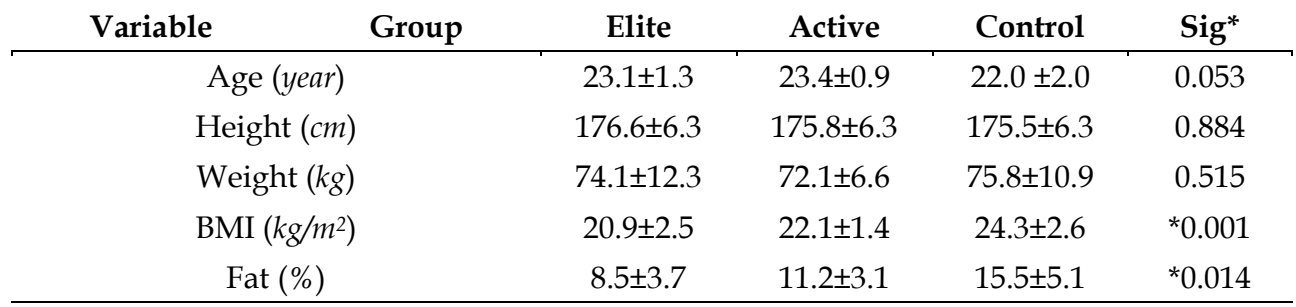

BMI $=$ Body Mass Index.

*: $\mathrm{P}<0.05$, significant difference between groups.

Table 1. Individual physical characteristics of subjects.

All subjects were given clear instructions on how to collect their semen at site. Each subject collected one semen sample by masturbation into a sterile container after at least 3-4 days of abstinence from ejaculations (Chia et al., 1998; Nikoobakht et al., 2005; Kao et al., 2008). The majorities of samples were provided on site or were delivered to the laboratory within 30 min of collection. Each subject also completed a questionnaire concerning the duration (days) of the abstinence before collecting each sample (Jeuilin et al., 1989).

\subsection{Seminal SOD activity measurement}

Semen analyses were performed according to WHO guidelines (Caballero et al., 1992; Nikoobakht et al., 2005). Semen evaluations were performed on each sample by the same experienced technician throughout the study, for the assessment of SOD activity. All of the semen samples were then cryopreserved using the Test Yolk Buffer with Glycerol as a freezing medium, according to the protocol described in WHO guidelines (4-th edition, 1999).

SOD activity was measured by colorimetric assay (Zini et al., 2000 and 2002). The commercially available colorimetric method was used (Randox Laboratories Ltd, UK). This method employs xanthine and xanthine oxidase to generate superoxide radicals which react with 2-(4-iodophenyl)-3-(4-nitrophenol) - 5-phenyltetrazoliumchloride (I.N.T) to form red formazan dye. The SOD activity is then measured by the degree of inhibition of this reaction. One unit of SOD inhibits reduction of INT by $50 \%$ under the conditions of the assay. After thawing, the seminal plasma was diluted 30-fold with $10 \mathrm{mM}$ phosphate buffer, $\mathrm{pH}$ 7.0. The assay was performed at $37^{\circ} \mathrm{C}$. Phosphate buffer was used as blank. Mixed 
substrate and xanthine oxidase were added into standards and sample tubes and vortexed well. With spectrophotometer adjusted at a wavelength of $505 \mathrm{~nm}$, the initial absorbance (A1) was read. Final absorbance (A2) was read exactly after 3 minutes, and percentages of inhibition of standards and samples were calculated. The SOD activity was measured using calibration curve of percentage inhibition for each standard against Log10 of standards and SOD activity was expressed as IU/ml.

\subsection{Statistical analysis}

Data are expressed as means $\pm \mathrm{SD}$. Differences among groups were determined by analysis of variance (ANOVA) for continuous variables. If the F-ratio was significant, differences among groups were subsequently identified using a Bonferroni post-hoc analysis. The statistical software program SPSS for windows, version 17.0 was used for all data analyses. All statistical tests were performed at a significance level of 0.05 .

\section{Results}

Semen parameters (mean \pm SD) were compared between study groups and the results are shown in Table 2. No significant differences were observed between groups in semen parameters $(\mathrm{P}>0.05)$ except of normal morphology $(\mathrm{P} \leq 0.05)$. The result of Bonferroni test showed that the observed difference is more pronounced between elite group with active and control groups. However, there was no significant difference between active and control groups.

At this study the seminal SOD activity $(\mathrm{IU} / \mathrm{ml})$ of 3 groups was investigated. One-way ANOVA analysis showed that there is a significant difference between three groups (Table 2). The result of Bonferroni analysis revealed significantly higher SOD activity in seminal plasma of elite group than those of active and control groups $(\mathrm{P} \leq 0.05)$. However, no statistically significant difference was observed between active and control groups $(\mathrm{P}>0.05)$.

\begin{tabular}{ccccc} 
Group & Elite & Active & Control & Sig* $^{*}$ \\
\hline Total sperm count $($ millions $)$ & $89.6 \pm 55.1$ & $86.2 \pm 52.9$ & $87.4 \pm 54.5$ & 0.089 \\
Volume $(m l)$ & $3.3 \pm 1.4$ & $2.7 \pm 1.2$ & $2.3 \pm 1.3$ & 0.071 \\
Concentration $(\times 106 / m l)$ & $56.6 \pm 2.9$ & $51.7 \pm 2.6$ & $53.5 \pm 2.8$ & 0.123 \\
Motility $(\%)$ & $72.8 \pm 15.6$ & $66.2 \pm 16.1$ & $69.7 \pm 14.9$ & 0.068 \\
Viability $(\%)$ & $80.5 \pm 13.5$ & $77.9 \pm 12.9$ & $74.7 \pm 13.8$ & 0.059 \\
Normal morphology $(\%)$ & $31.4 \pm 10.6$ & $19.1 \pm 11.4$ & $23.7 \pm 10.1$ & $* 0.034$ \\
SOD $(I U / m l)$ & $34.3 \pm 9.4$ & $17.9 \pm 5.6$ & $24.2 \pm 6.6$ & $* 0.001$ \\
\hline
\end{tabular}

*: $\mathrm{P}<0.05$, significant difference between groups.

Table 2. Comparison of Semen parameters and SOD activity between elite athletes, recreationally active and sedentary men.

\section{Discussion}

The results emerging from this study show that semen from elite athletes have higher SOD content than those of the active and sedentary (control) men. However, no significant difference was observed between samples of active and control groups. Therefore, these results represent that elite athletic men have developed seminal antioxidant capacity at least 
in the case of SOD, suggesting that spermatozoa from elite athletes may be less susceptible to ROS-induced peroxidative damage, and hence, infertility. ROS have been shown to cause infertility by directly damaging the sperm DNA (Tremellen, 2008). Spermatozoa are susceptible to oxidative damage because their plasma membranes are rich in polyunsaturated fatty acids and have low concentrations of scavenging enzymes. SOD as one of the important elements of seminal plasma superoxide anion scavenging capacity plays an essential role in maintaining the balance between ROS generation and degradation through preventing increases in ROS concentration. Due to the protective effects against peroxidative damage and oxidative stress, seminal SOD has been shown to preserve sperm motility and viability. Sperm motility has been found to associate with men fertility (Jones et al., 1979; Smith et al., 1996; Murawski et al., 2007; Agarwal et al., 2008). The essential role of SOD as antioxidative defense enzyme is inferred from the observation that complete loss of motility of a sperm sample is directly proportional to the SOD activity of that sample (Storey, 1997). In particular, low SOD activity has been shown to be responsible for male infertility (Alkan et al., 1997). Several investigators have reported reductions in SOD activity in semen of infertile men (Alkan et al., 1997; Sanocka et al., 1997; Siciliano et al., 2001), although some have not (Zini et al., 1993; Miesel et al., 1997; Hsieh et al., 2002). Recently Murawski et al. (2007) reported a significantly lower semen SOD activity in infertile men, as compared with normospermic men. They showed a positive correlation between SOD activity in seminal plasma and semen quality parameters - sperm concentration and overall motility, which are regarded as the most important for normal fertilizing ability of the spermatozoa (Murawski et al., 2007).

Although the protective effect of seminal plasma has been well recognized, no study has investigated its antioxidative properties in individuals with different fitness level, in particular in athletic men. To the best of our knowledge, the present study provides the first evidence that elite athletes have an augmented SOD capacity than recreationally active and sedentary control men. Although there is no definitive explanation for this discrepancy, but the notion that high maximal oxygen uptake $\left(\mathrm{VO}_{2 \mathrm{max}}\right)$, which is a consequence of systemic endurance training (Tanaka and Swensen, 1998), are correlated to elevated antioxidant enzyme activity in other tissues (Jenkins et al., 1984), can explain some of the disparities in our study. These observations suggest that the fitness level of subject as well as the type and amount of exercise training could be taken into consideration when comparing antioxidant capacity of active people. As the active group in our study were exercising just $4-5 \mathrm{~h}$ per week, it seems possible that this amount of exercise is not enough to enhance antioxidant capacity. Dekany et al. (2006) have also referred to fitness level of athletes and type of exercise as important factors determining the blood level of antioxidant enzymes (Dekany et al., 2006). In the review by Clarkson (1995) it has been documented that the "weekend athlete" may not have the augmented antioxidant defense system produced through continued training (Clarkson, 1995). This may make them more susceptible to oxidative stress.

The fact that rigorous exercise training programs may be required to promote antioxidant enzyme activity in skeletal muscle (Powers and Leeuwenburgh, 1999), can support our results. Intensive endurance training has been postulated as a potential muscle`s antioxidant defense system up-regulator (Fatouros et al., 2004). Powers et al. (1994) experimentally analyzed the relationship between the magnitude of the training stimulus (i.e., exercise intensity and daily duration) and the activity of SOD in locomotor skeletal muscles. Nine groups of rats ran at three different daily durations (i.e., 30, 60, 90 min.d) and three different exercise intensities (i.e., 55,65 , and $75 \%$ of $\mathrm{VO}_{2 \max }$ ) (Powers et al., 1994). Furthermore, previous studies have reported 
that high-intensity running training can elevate antioxidant enzyme activities in erythrocytes and decrease neutrophil superoxide anion production both at rest and in response to exhaustive acute exercise (Miyazaki et al., 2001). These data clearly show that high intensity long-term exercise training is superior to recreationally exercise in the up-regulation of seminal plasma SOD activity, representing adaptation to regular training. In fact, the training-stressed cells provide high antioxidant enzyme content. It has been generally believed that training induction of antioxidant enzymes is a cellular adaptation to oxidative stress caused by free radical generation during heavy exercises (Jenkins, 1988; Ji, 1998).

Prior to this work, numerous studies have been published focusing on the adaptation of different tissue's antioxidant capacity to exercise training (Mena et al., 1991; Ortenblad et al., 1997; Ji, 1998; Suzuki et al., 2000; Banfi et al., 2006; Dekany et al., 2006; Tayler et al., 2006; Garcia-Lopez et al., 2007; Niess et al., 2007). Recently Garcia Lopez et al. (2007) showed an increase in MnSOD mRNA levels of peripheral mononuclear cell (PBMC) in response to endurance training in middle-aged men (Garcia-Lopez et al., 2007). Tauler et al. (2006) reported an increase in erythrocyte superoxide dismutase activity after the training/competition period for amateur trained male athletes (Tayler et al., 2006). Banfi et al. (2006) showed a significantly higher plasma Glutathione reductase (GR) activity in trained elite soccer players, as compared with sedentary controls (Banfi et al., 2006). Investigating antioxidant status of interval-trained athletes, Dekany et al. (2006) reported high level of blood enzymatic antioxidants in highly trained athletes (Dekany et al., 2006). Ravi et al. (2004) showed a significantly increase in myocardium superoxide dismutase after 4 weeks low-intensity swim training in rats (Ravi et al., 2004). Also, Yamamoto et al. (2002) reported higher superoxide dismutase activity and antioxidant capacity for physically active rats in compared to sedentary rats (Yamamoto et al., 2002). However, both in treadmilltrained rats (Leeuwenburgh et al., 1994) and running trained humans (Tiidus et al., 1996) endurance training did not affect antioxidant defense.

Some limitations of the present study should be taken into consideration. First, we measured the SOD activity just in seminal plasma and did not measure in spermatozoa. Secondly, five subjects (active group $n=2$, and control group $n=3$ ) could not provide the semen sample in time and were excluded from the study. This might influence the compared results. Thirdly, this study comprised a relatively small sample thus limiting statistical power to detect differential effects. However, this is, to our knowledge, the first study analyzed the seminal antioxidant activity in individuals with different level of physical fitness.

In conclusion, the results of present study demonstrate that in compared to recreationally active and sedentary men, the elite athletes have developed SOD capacity. The mechanisms responsible for this increase are unknown and remain an active area of research. However, this raises the question that does the training-induced increase in seminal plasma SOD capacity provide increased protection against ROS-induced sperm dysfunction and infertility in high level athletes? If it does, we are able to provide novel insights into athletic health and male fertility. Further studies are warranted to deal the antioxidant capacity of seminal plasma and spermatozoa of individuals with different level of physical fitness as well as the effect of various exercise programs on seminal antioxidant capacity.

\section{Acknowledgment}

We would like to thank the subjects for their participation and effort. This research did not receive any specific grant from any funding agency in the public, commercial or not-forprofit sector. 


\section{References}

Agarwal, A. Prabakaran, S. \& Allamaneni, S. (2006). What an andrologist/urologist should know about free radicals and why? Journal of Urology, 67 (1): 2-8, ISSN 00904295.

Agarwal, A. Kartikeya, M. \& Sharma, R. (2008). Clinical relevance of oxidative stress in male factor infertility: an update. American Journal of Reproductive Immunology, 59 (1): 211, ISSN 1677-5538.

Aitken, RJ. \& Clarkson, JS. (1987). Cellular basis of defective sperm function and its association with the genesis of reactive oxygen species by human spermatozoa. Journal of Reproduction and Fertility, 81 (2): 459-469, ISSN 0022-4251.

Aitken, RJ. Irvine, MD. \& Wu, FC. (1989). Prospective analysis of sperm-oocyte fusion and reactive oxygen species generation as criteria for the diagnosis of infertility. American Journal of Obstetrics and Gynecology, 164 (2): 542-551, ISSN 0002-9378.

Alkan, I. Simsek, F. Haklar, G. Kervancioglu, E. Ozveri, H. Yalcin, S. \& Akdas, A. (1997). Reactive oxygen species production by the spermatozoa of patients with idiopathic infertility: relationship to seminal plasma antioxidants. Journal of Urology, 157 (1): 140-143, ISSN 00904295.

Banfi, G. Malavazos, A. Iorio, E. Dolci, A. Doneda, L. Verna, R. \& Corsi, MM. (2006). Plasma oxidative stress biomarkers, nitric oxide and heat shock protein 70 in trained elite soccer players. European Journal of Applied Physiology, 96(5): 483-486, ISSN 14396319.

Caballero, MJ. Mena, P. \& Maynar, M. (1992). Changes in sex hormone binding globulin, high density lipoprotein cholesterol and plasma lipids in male cyclists during training and competition. European Journal of Applied Physiology and Occupational Physiology, 64 (1): 9-13, ISSN 1432-1025.

Chia, SE. Tay, SK. \& Lim, ST. (1998). What constitutes a normal seminal analysis? Semen parameters of 243 fertile men. Human Reproduction, 13 (12): 3394-3398, ISSN 02681161.

Clarkson, PM. (1995). Antioxidants and physical performance. Critical Review in Food Science and Nutrition, 35(1-2): 131-141, ISSN 1040-8398.

Dekany, M. Nemeskeri, V. Györe, I. Harbula, I. Malomski, J. \& Pucsok, J. (2006). Antioxidant status of interval-trained athletes in various sports. International Journal of Sports Medicine, 27(2): 112-116, ISSN 0172-4622.

De Lamirande, E. \& Gagnon, C. (1993). Human sperm hyperactivation in whole semen and its association with low superoxide scavenging capacity in seminal plasma. Fertility and Sterility, 59 (6): 1291-1295, ISSN 1556-5653.

Di Luigi, L. Gentile, V. Pigozzi, F. Parisi, A. Giannetti, D. \& Romanelli, F. (2001). Physical activity as a possible aggravating factor for athletes with caricocele: impact on the semen profile. Human Reproduction, 16 (6): 1180-1184, ISSN 0268-1161.

Fatouros, IG. Jamurtas, AZ. Villiotou, V. Pouliopoulou, S. Fotinakis, P. Taxildaris, K. \& Deliconstantinos, G. (2004). Oxidative stress responses in older men during endurance training and detraining. Medicine and Science in Sports and Exercise, 36 (12): 2065-2072, ISSN 1530-0315.

Fujii, J. Iuchi, Y. Matsuki, S. \& Ishii, T. (2003). Cooperative function of antioxidant and redox systems against oxidative stress in male reproductive tissues. Asian Journal of Andrology, 5 (3): 231-242, ISSN 1008-682X. 
Garcia-Lopez, D. Häkkinen, K. Cuevas, MJ. Lima, E. Kauhanen, A. Mattila, M. Sillanpää, E. Ahtiainen, JP. Karavirta, L. Almar, M. \& González-Gallego, J. (2007). Effects of strength and endurance training on antioxidant enzyme gene expression and activity in middle-aged men. Scandinavian Journal of Medicine and Science in Sports, 17 (5): 595-604, ISSN 0905-7188.

Garrido N, Meseguer M, Simon C, Pellicer A \& Remohi J. (2004). Pro-oxidative and antioxidative imbalance in human semen and its relation with male fertility. Asian Journal of Andrology, 6 (1): 59-65, ISSN 1008-682X.

Hsieh, YY. Sun, YL. Chang, CC. Lee, YS. Tsai, HD. \& Lin, CS. (2002). Superoxide dismutase activities of spermatozoa and seminal plasma are not correlated with male infertility. Journal of Clinical and Laboratory Analysis, 16 (3): 127-131, ISSN 1098-2825.

Iwasaki, A. \& Gagnon, C. (1992). Formation of reactive oxygen species in spermatozoa of infertile patients. Fertility and Sterility, 57 (2): 409-416, ISSN 1556-5653.

Jenkins, RR. Friedland, R. \& Howald, H. (1984). The relationship of oxygen consumption to superoxide dismutase and catalase activity in human skeletal muscle. International Journal of Sports Medicine, 5 (1): 11-14, ISSN 0172-4622.

Jenkins, R. (1988). Free radical chemistry: relationship to exercise. Sports Medicine, 5 (3): 156170, ISSN 0112-1642.

Jeuilin, C. Soufir, JC. \& Weber, P. (1989). Catalase activity in human spermatozoa and seminal plasma. Gamete Research, 24 (2): 185-191, ISSN 0148-7280.

Ji, LL. (1998). Antioxidant enzyme response to exercise and training in the skeletal muscle. In: Oxidative Stress in skeletal muscle, ed. A.Z. Reznik. L. Packer, C.K. Sen, J.O. Holloszy \& M.J,Jackson, 103-125. Basel: Bikhaeuser Verlag.

Jones, R. Mann, T. \& Shenns, R. (1979). Peroxidative breakdown of phosphohpids in human spermatozoa, spermicidal properties of fatty acid peroxides, and protective action of seminal plasma. Fertility and Sterility, 31 (5): 531-537, ISSN 1556-5653.

Kao, SH. Chao, HT. Chen, HW. Hwang, TI. Liao, TL. \& Wei, YH. (2008). Increase of oxidative stress in human sperm with lower motility. Fertility and Sterility, 89(5): 1183-1190, ISSN 1556-5653.

Kobayashi, T. Miyazaki, T. Natori, M. \& Nozawa, S. (1991). Protective role of superoxide dismutase in human sperm motility: superoxide dismutase activity and lipid peroxide in human seminal plasma and spermatozoa. Human Reproduction, 6 (7): 987-991, ISSN 0268-1161.

Leeuwenburgh, C. Fiebig, R. Chandwaney, R. \& Ji, LL. (1994). Aging and exercise training in skeletal muscle: responses of glutathione and antioxidant enzyme systems. American Journal of Physiology, 267 (2): 439-445, ISSN 0363-6143.

Lucía, A. José, L. Chicharro, A. Pérez, M. Serratosa, L. Bandrés, F. \& Legido, JC. (1996). Reproductive function in male endurance athletes: sperm analysis and hormonal profile. Journal of Applied Physiology, 81 (6): 2627-2636, ISSN 8750-7587.

Mena, P. Maynar, M. Gutierrez, JM. Maynar, J. Timon, J. \& Campillo, JE. (1991). Erythrocyte free radical scavenger enzymes in bicycle professional racers, adaptation to training. International Journal of Sports Medicine, 12 (6):563-566, ISSN 0172-4622.

Miesel, R. Jedrzejczak, P. Sanocka, D. \& Kurpisz, MK. (1997). Severe antioxidase deficiency in human semen samples with pathological spermiogram parameters. Andrologia, 29 (2): 77-83, ISSN 0303-4569. 
Miyazaki, H. Oh-ishi, S. Ookawara, T. Kizaki, T. Toshinai, K. Ha, S. Haga, S. Ji, LL. \& Ohno, H. (2001). Strenuous endurance training in humans reduces oxidative stress following exhausting exercise. Journal of Applied Physiology, 84 (1-2): 1-6, ISSN 87507587.

Murawski, M. Saczko, J. Marcinkowska, A. Chwikowska, A. Grybooe, M. \& Banaoe, T. (2007). Evaluation of superoxide dismutase activity and its impact on semen quality parameters of infertile men. folia histochemica et cytobiologica, 45 (1): 123-126, ISSN 02398508.

Niess, AM. \& Simon, P. (2007). Response and adaptation of skeletal muscle to exercise: the role of reactive oxygen species. Frontiers in Bioscience, 1 (12): 4826-4838, ISSN 10939946.

Nikoobakht, M. Aloosh, M. \& Hasani, M. (2005). Seminal Plasma Magnesium and Premature Ejaculation: a Case-Control Study. Journal of Urology, 2 (2): 102-105, ISSN 00904295.

Nissen, HP. \& Kreysel, HWA. (1983). Superoxide dismutase in human semen. Klin Wochenschr, 61 (1): 63-65, ISSN 0023-2173.

Ochsendorf, FR. Thiele, J. Fuchs, J. Schuttau, H. Freisleben, HJ. Buslau, M. \& Milbradt, R. (1994). Chemiluminescence in semen of infertile men. Andrologia, 26 (5): 289-293, ISSN 0303-4569.

Ortenblad, N. Madsen, K. \& Djurhuus, MS. (1997). Antioxidant status and lipid peroxidation after short term maximal exercise in trained and untrained humans. American Journal of physiology, 272 (2): 1258-1263, ISSN 0363-6143.

Powers, SK. Criswell, D. Lawler, J. Ji, LL. Martin, D. Herb, RA. \& Dudley, G. (1994). Influence of exercise and fiber type on antioxidant enzyme activity in rat skeletal muscle. American Journal of physiology. 266 (2): 375-380, ISSN 0363-6143.

Powers, SK. \& Leeuwenburgh, C. (1999). Exercise training-induced alterations in skeletal muscle antioxidant capacity: a brief review. Medicine and Science in Sport and Exercise, 31 (7): 987-997, ISSN 1530-0315.

Ravi, KT. Subramanyam, MV. \& Asha, DS. (2004). Swim exercise training and adaptation in the antioxidant defense system of myocardium of old rats: relationship to swim intensity and duration. Comparative Biochemistry and Physiology Part B: Biochemistry and Molecular Biology, 137 (2): 187-196, ISSN 1095-6433.

Sanocka, D. Miesel, R. Jedrzejczak, P. Chelmonska-Soyta, AC. \& Kurpisz, M. (1997). Effect of reactive oxygen species and the activity of antioxidant systems on human semen; association with male infertility. International Journal of Andrology, 20 (5): 255-264, ISSN 1365-2605.

Shekarriz, M. Thomas, AJ. \& Agarwal, A. (1995). Incidence and level of seminal reactive oxygen species in normal men. Journal of Urology 45 (1): 103-107, ISSN 00904295.

Siciliano, L. Tarantino, P. Longobardi, F. Rago, V. De Stefano, C. \& Carpino, A. (2001). Impaired seminal antioxidant capacity in human semen with hyperviscosity or oligoasthenozoospermia. Journal of Andrology, 22 (5): 798-803, ISSN 0196-3635.

Smith, R. Vantman, J. Ponce, J. Escobar, A. \& Lissi, E. (1996). Total antioxidant capacity of human seminal plasma. Human Reproduction, 11 (8): 1655-1660, ISSN 0268-1161.

Storey, BT. (1997). Biochemistry of the induction and prevention of lipoperoxidative damage in human spermatozoa. Molecular Human Reproduction, 3 (3): 203-213, ISSN 13609947. 
Suzuki K, Ohno H, Oh-ishi S, Kizaki T, Ookawara T, Fujii J, Radák Z, and Taniguchi N. Superoxide dismutases in exercise and disease. In: Handbook of Oxidants and Antioxidants in Exercise, edited by Sen CK, Packer L, and Hänninen O. Amsterdam: Elsevier, 2000, p. 243-295.

Tanaka, H. \& Swensen, T. (1998). Impact of resistance training on endurance performance. A new form of cross-training. Sports Medicine, 25 (3): 191-200, ISSN 0112-1642.

Tayler, P. Aquilo, A. Gimeno, I. Fuentespina, E. Tur, JA. \& Pons, A. (2006). Response of blood cell antioxidant enzyme defence to antioxidant diet supplementation and to intense exercise. European Journal of Nutrition, 45 (4): 187-195, ISSN 1436-6215.

Tiidus, PM. Pushkarenko, J. \& Houston, ME. (1996). Lack of antioxidant adaptation to shortterm aerobic training in human muscle. American Journal of Physiology. 271 (4): 832836, ISSN 0363-6143.

Tremellen, K. (2008). Oxidative stress and male infertility-a clinical perspective. Human Reproduction Update, 14 (3): 243-258, ISSN 1355-4786.

Yamamoto, T. Ohkuwa, T. Itoh, H. Sato, Y. \& Naoi, M. (2002). Effect of gender differences and voluntary exercise on antioxidant capacity in rats. Comparative Biochemistry and Physiology Part C: Toxicology and Pharmacology, 132 (4): 437-444, ISSN 1532-0456.

Zini, A. de Lamirande, E. \& Gagnon, C. (1993). Reactive oxygen species in semen of infertile patients: levels of superoxide dismutase- and catalase-like activities in seminal plasma and spermatozoa. International Journal of Andrology, 16 (3): 183-188, ISSN 1365-2605.

Zini, A. Garrels, K. \& Phang, D. (2000). Antioxidant activity in the semen of fertile and infertile men. Urology, 55 (6): 922-926, ISSN 00904295. 


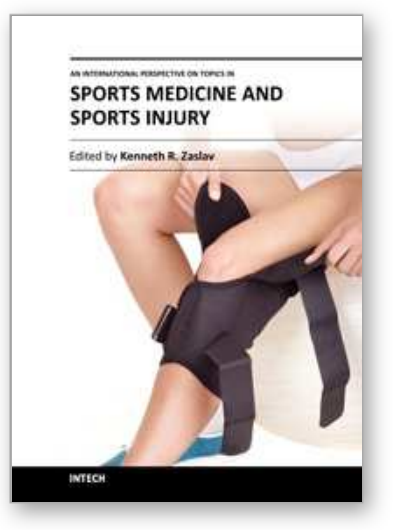

\author{
An International Perspective on Topics in Sports Medicine and \\ Sports Injury \\ Edited by Dr. Kenneth R. Zaslav
}

ISBN 978-953-51-0005-8

Hard cover, 534 pages

Publisher InTech

Published online 17, February, 2012

Published in print edition February, 2012

For the past two decades, Sports Medicine has been a burgeoning science in the USA and Western Europe. Great strides have been made in understanding the basic physiology of exercise, energy consumption and the mechanisms of sports injury. Additionally, through advances in minimally invasive surgical treatment and physical rehabilitation, athletes have been returning to sports quicker and at higher levels after injury. This book contains new information from basic scientists on the physiology of exercise and sports performance, updates on medical diseases treated in athletes and excellent summaries of treatment options for common sports-related injuries to the skeletal system.

\title{
How to reference
}

In order to correctly reference this scholarly work, feel free to copy and paste the following:

Bakhtyar Tartibian, Behzad Hajizadeh Maleki, Asghar Abbasi, Mehdi Eghbali, Siamak Asri-Rezaei and Hinnak Northoff (2012). Comparison of Seminal Superoxide Dismutase (SOD) Activity Between Elite Athletes, Active and Non Active Men, An International Perspective on Topics in Sports Medicine and Sports Injury, Dr. Kenneth R. Zaslav (Ed.), ISBN: 978-953-51-0005-8, InTech, Available from: http://www.intechopen.com/books/aninternational-perspective-on-topics-in-sports-medicine-and-sports-injury/comparison-of-seminal-superoxidedismutase-sod-activity-between-elite-athletes-active-and-non-active

\section{INTECH}

open science | open minds

\author{
InTech Europe \\ University Campus STeP Ri \\ Slavka Krautzeka 83/A \\ 51000 Rijeka, Croatia \\ Phone: +385 (51) 770447 \\ Fax: +385 (51) 686166 \\ www.intechopen.com
}

\author{
InTech China \\ Unit 405, Office Block, Hotel Equatorial Shanghai \\ No.65, Yan An Road (West), Shanghai, 200040, China \\ 中国上海市延安西路65号上海国际贵都大饭店办公楼 405 单元 \\ Phone: +86-21-62489820 \\ Fax: +86-21-62489821
}


(C) 2012 The Author(s). Licensee IntechOpen. This is an open access article distributed under the terms of the Creative Commons Attribution 3.0 License, which permits unrestricted use, distribution, and reproduction in any medium, provided the original work is properly cited. 